\title{
Evolution of microstructure and mechanical properties of Ti-based metal-matrix composites during hot deformation
}

\author{
S. Zherebtsov ${ }^{\text {a, }}$, M. Ozerov ${ }^{\text {a }}$, M. Klimova ${ }^{\text {a }}$, D. Klimenko ${ }^{\text {a }}$, V. Sokolovsky ${ }^{\text {a }}$, N. Stepanov ${ }^{\text {a }}$ \\ ${ }^{\text {a }}$ Belgorod National Research University, Belgorod, Russia \\ *ser_z@mail.ru
}

\begin{abstract}
$\underline{\text { Abstract }}$
Two Ti-based composites, viz. Ti/TiB and $\mathrm{Ti}-15 \mathrm{Mo} / \mathrm{TiB}$ were produced by spark plasma sintering using a $\mathrm{Ti}-10 \mathrm{wt} . \% \mathrm{TiB} 2$ powder mixture at $1000^{\circ} \mathrm{C}$ or $\mathrm{Ti}-$ 14.25 (wt.) $\% \mathrm{Mo}-5$ (wt.) $\% \mathrm{TiB} 2$ powder mixture at $1400^{\circ} \mathrm{C}$, respectively. Specimens of the metal-matrix composites (MMCs) were subjected to uniaxial compression in the temperature range from 500 to $1050^{\circ} \mathrm{C}$ to determine processing window. Processing maps for both MMCs were constructed and analyzed. Mechanical behavior and microstructure evolution of both MMCs during multiaxial forging (MAF) at $700^{\circ} \mathrm{C}$ and at a strain rate $10^{-3} \mathrm{~s}^{-1}$ were studied. The flow stress for the Ti- $15 \mathrm{Mo} / \mathrm{TiB} \mathrm{MMC}$ during MAF was $\sim 2$ times higher than that for the Ti/TiB composite. Microstructure evolution during MAF of Ti/TiB MMC was associated with continuous dynamic recrystallization of the titanium matrix and shortening of $\mathrm{TiB}$ whiskers by a factor of $\sim 3$. The Ti-15Mo/TiB composite microstructure after did not demonstrate the development of recrystallization.
\end{abstract}

\section{Introduction}

Due to attractive properties (low density, high specific strength, corrosion resistance, biocompatibility), titanium and titanium alloys have various industrial and bio-medical applications [1]. However, the use of titanium and titanium alloys is often limited due to insufficiently high absolute strength, hardness and wear resistance.

Hardening of titanium can be achieved by creating titanium-matrix composite materials reinforced with hard compounds like TiB, TiC or TiN [2, 3]. Among these reinforcements $\mathrm{TiB}$ is preferable because of high stability at elevated temperatures, close to titanium density and thermal expansion coefficient, as well as good crystallographic interfaces with a titanium matrix [3]. Spark plasma sintering (SPS) can be used for the Ti/TiB composite synthesis; the chemical reaction Ti $+\mathrm{TiB} 2=2 \mathrm{TiB}$ during the synthesis results in the formation of hard TiB whiskers in the titanium matrix. SPS allows synthesis at relatively low temperature and for a short time that ensures high performance of the method and does not lead to a significant coarsening of structural elements thereby allowing obtaining nanostructure in the composite of a good density [4]

At the same time, the presence of the TiB hardening phase in the composite results not only in high strength but also in insufficient ductility, especially at low temperatures [5-8]. One of the possible approaches to increase the ductility of the Ti/TiB composite is thermo-mechanical treatment. For example, a noticeable improvement in the mechanical properties of the $\mathrm{Ti} / \mathrm{TiB}$ composite due to deformation was reported in [9-13]

Another possible option to improve properties of the Ti/TiB composite can be associated with using various crystalline condition of the titanium matrix; for example changing of the matrix structure from the hexagonal close-packed (hcp) lattice to the body-centered cubic (bcc) one via addition of a beta stabilizer(s) can result in some change of ductility of the composite due activation of a greater number of slip systems. The strength and hardness of $b$ titanium alloys with a (meta)stable bcc structure can also be considerably enhanced by thermomechanical treatment [14]

However, currently there is not enough information in literature which allow determining the parameters of the deformation-heat treatment of the composites with a different titanium matrix structure, as well as the possible level of mechanical properties which can be attained. Thus, the purpose of this work was to establish the effect of plastic deformation on structure and properties of the Ti/TiB and Ti-15Mo/TiB composites obtained by the SPS method.

\section{Material and experiments}

Commercial purity powders of $\mathrm{Ti}\left(99.1 \%\right.$ purity), Mo ( $99.95 \%$ purity) and $\mathrm{TiB}_{2}(99.9 \%$ purity) were used for the sintering of either $\mathrm{Ti} / \mathrm{TiB}$ (with hep $\mathrm{Ti}$ matrix) or Ti-15 Mo/TiB (with bcc Ti matrix) composites. The average sizes of the Ti, Mo and TiB 2 particles in the powders were 25,20 and $4 \mu \mathrm{m}$, respectively. A powders mixture contained 90 wt. $\%$ Ti and 10 wt. $\% \mathrm{TiB}_{2}$ (to obtain the Ti/TiB ) or 80.75 wt. $\%$ Ti, 14.25 wt. $\%$ of Mo and 5 wt. $\%$ of TiB 2 (to obtain a Ti-15wt.\% Mo alloy with 8.5 vol.\% of $\mathrm{TiB}$ ) were produced using a Retsch RS200 vibrating cup mill in ethanol for $1 \mathrm{~h}$; a milling rotation speed was $700 \mathrm{rpm}$.

$\mathrm{Ti} / \mathrm{TiB}$ metal-matrix composites were produced using the SPS process under vacuum using a Thermal Technology SPS $10-3$ at $1000^{\circ} \mathrm{C}(\mathrm{b}$-phase field) at $40 \mathrm{MPa}$ for $15 \mathrm{~min}$. Specimens of Ti-15\% Mo/TiB MMC were produced by SPS at a higher temperature $\left(1400^{\circ} \mathrm{C}\right.$, to ensure solution of refractory Mo in the Ti matrix $)$ and $40 \mathrm{MPa}$ under vacuum for $15 \mathrm{~min}$. The specimens measuring $15 \mathrm{~mm}$ in height and $19 \mathrm{~mm}$ in diameter were obtained in both cases. Homogenization annealing of the Ti-15\%Mo/TiB MMC was additionally carried out at $1200^{\circ} \mathrm{C}$ for $24 \mathrm{~h}$. Prior to homogenization, the samples were sealed in vacuumed quartz tubes filled with titanium chips to prevent oxidation. After annealing, the tubes were removed from the furnace and the samples were cooled inside the vacuumed tubes down to room temperature due to heat exchange with the surrounding air.

Specimens $Æ 7^{\prime} 10 \mathrm{~mm}$ were cut from the composite preforms of both conditions using an electro-discharge machine Sodick AQ300L. The specimens were compressed isothermally in air at $500^{\circ} \mathrm{C}, 700^{\circ} \mathrm{C}, 850^{\circ} \mathrm{C}, 950^{\circ} \mathrm{C}, 1000^{\circ} \mathrm{C}$ or $1050^{\circ} \mathrm{C}$ (in the case of Ti/TiB) or at $500^{\circ} \mathrm{C}, 600^{\circ} \mathrm{C}, 700^{\circ} \mathrm{C}, 800^{\circ} \mathrm{C}, 900^{\circ} \mathrm{C}$ or $1000^{\circ} \mathrm{C}$ (in the case of $\mathrm{Ti}-15 \% \mathrm{Mo} / \mathrm{TiB}$ ) on an Instron mechanical testing machine at a nominal strain rate of $10^{-3} \mathrm{~s}^{-1}$ to a true strain $\varepsilon \approx 1.2$ (corresponding to $70 \%$ height reduction). The holding time of the specimen at the desired temperature before the start of deformation was 15 minutes. Immediately after stopping the deformation, the sample was removed from the furnace and cooled on air.

Prismatic samples measured $16^{\prime} 14^{\prime} 12 \mathrm{~mm}^{3}$ were cut from the composites using an electric-discharge machine. The specimens were subjected to the multiaxial forging (MAF) which comprised successive compressions of a sample along three orthogonal directions [15] with the recording of stress-strain curves of each deformation step. A prismatic shape was restored to the samples by electric-discharge machining the curved faces prior to each rotation. The initial strain rate and the true strain per deformation step were $10^{-3} \mathrm{~s}^{-1}$ and $\sim 0.5$, respectively. Compressions were performed on an Instron $300 \mathrm{LX}$ testing machine in the laboratory air at $700^{\circ} \mathrm{C}$. Ten compressions in total were made that correspond to the cumulative strain $\mathrm{Se} » 5.2$.

The microstructure in the axial section was studied using a scanning electron microscope (SEM) FEI Quanta 600 FEG microscope and a transmission electron microscope (TEM) JEOL JEM 2100. Etching was carried out with Kroll's reagent (95\% H2O, 3\% HNO3, 2\% HF) for SEM observations.

(C) The Authors, published by EDP Sciences. This is an open access article distributed under the terms of the Creative Commons Attribution License 4.0 (http://creativecommons.org/licenses/by/4.0/). 


\section{$\underline{\text { 3. Results and discussion }}$}

In the initial condition microstructure of the Ti/TiB composite consisted of TiB fibers (whiskers) non-uniformly distributed in the Ti matrix (either hep (Fig. 1a,b) or bec (Fig. 1d,e)) and some particles of residual $\mathrm{TiB}_{2}$. The average diameter of TiB whiskers in the Ti/TiB MMC was $36 \pm 15 \mathrm{~nm}$. Individual TiB whiskers cannot be distinguished in Fig. 1a; lighter areas contained more whisker in comparison with the darker ones. In the Ti-15\%Mo/TiB composite the average TiB fibers diameter was noticeably thicker $(130 \pm 65 \mathrm{~nm}$; in addition TiB whiskers of $\sim 1-2 \mu \mathrm{m}$ can also be observed) most likely due to higher sintering temperature. The TiB whiskers in the hep (Fig. 1c) or bec (Fig. 1f) Ti matrix can also be seen in TEM images. Dislocation density was generally rather high in both cases; however, in some places individual TiB whiskers can be clearly seen. Grain boundaries cannot be distinguished in the hep/bcc Ti matrix; however, the spacing between the TiB whiskers (which to a first approximation can be considered as a free dislocation path) was $\sim 0.2-0.3 \mathrm{~mm}$ in the hcp Ti matrix or $\sim 0.5-0.7 \mu \mathrm{m}$ in the case of bcc $\mathrm{Ti}$.
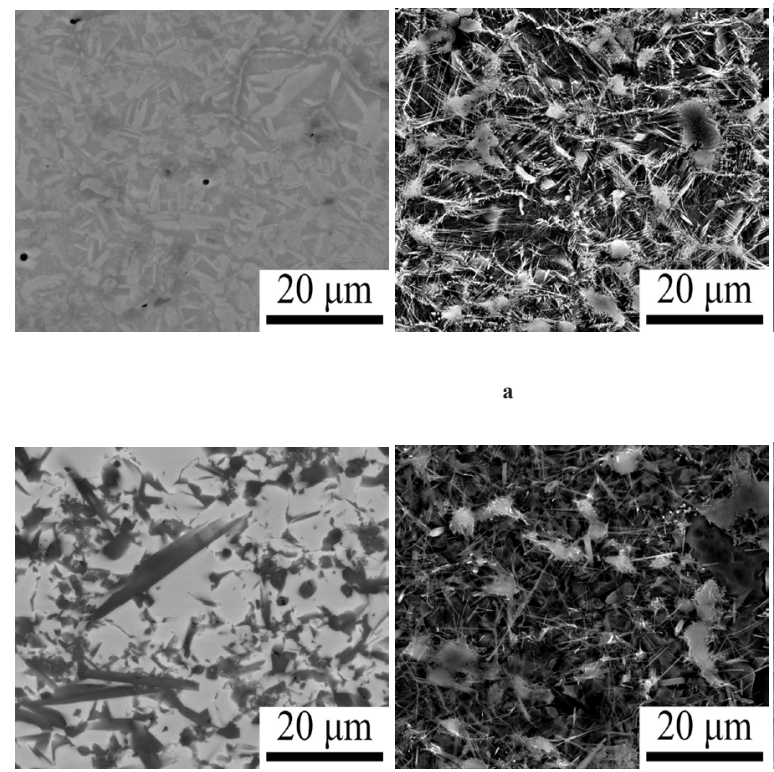

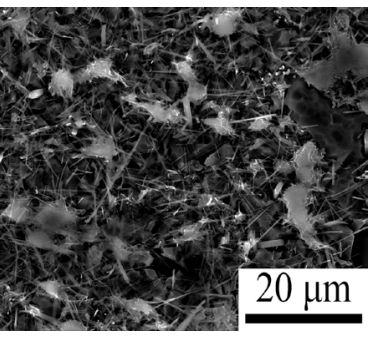

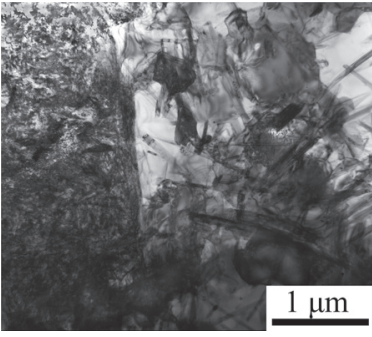

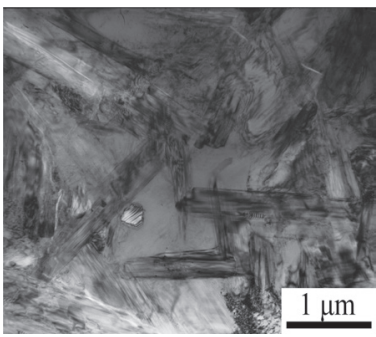

Figure 1. Initial microstructure of Ti/TiB and Ti-15\%Mo/TiB MMCs: (a, d) - SEM image of unetched surface; (b, e) - SEM image of etched surface; (c, f) - TEM bright field image, Ti/TiB (a-c), Ti-15Mo/TiB (d-f).

Mechanical behavior of the composites was studied during compression tests at temperatures $500-1050{ }^{\circ} \mathrm{C}(\mathrm{Ti} / \mathrm{TiB})$ or $500-1000^{\circ} \mathrm{C}(\mathrm{Ti}-15 \% \mathrm{Mo} / \mathrm{TiB})$. Compression of the $\mathrm{Ti} / \mathrm{TiB}$ composite at $500^{\circ} \mathrm{C}$ resulted in a steady-state flow during plastic strain which most likely was associated with localized shear deformation resulted in the specimen fracture. The stress-strain curves obtained at temperatures of $700-1050^{\circ} \mathrm{C}$ showed the presence of an initial hardening transient, the achievement of a peak flow stress, and then flow softening (Fig. 2). This behavior can be ascribed to the processes of dynamic recrystallization or recovery. In the case of Ti-15\%Mo/TiB MMC flow stress during deformation increased noticeably at 500 and $600^{\circ} \mathrm{C}$ while the dynamic recrystallization/recovery-like behavior was observed at temperatures $>700^{\circ} \mathrm{C}$. It should be noted much higher flow stress of the $\mathrm{Ti}-15 \% \mathrm{Mo} / \mathrm{TiB}$ composite at corresponding temperatures in spite of the lower volume fraction of $\mathrm{TiB}$. Fracture of the $\mathrm{Ti}-15 \% \mathrm{Mo} / \mathrm{Ti}$ specimen occurred at $\sim 33 \%$ during compression at $500^{\circ} \mathrm{C}$ while $\mathrm{Ti} / \mathrm{TiB}$ fractured at $24 \%$, therefore suggesting higher ductility of the composite based on the bcc Ti matrix
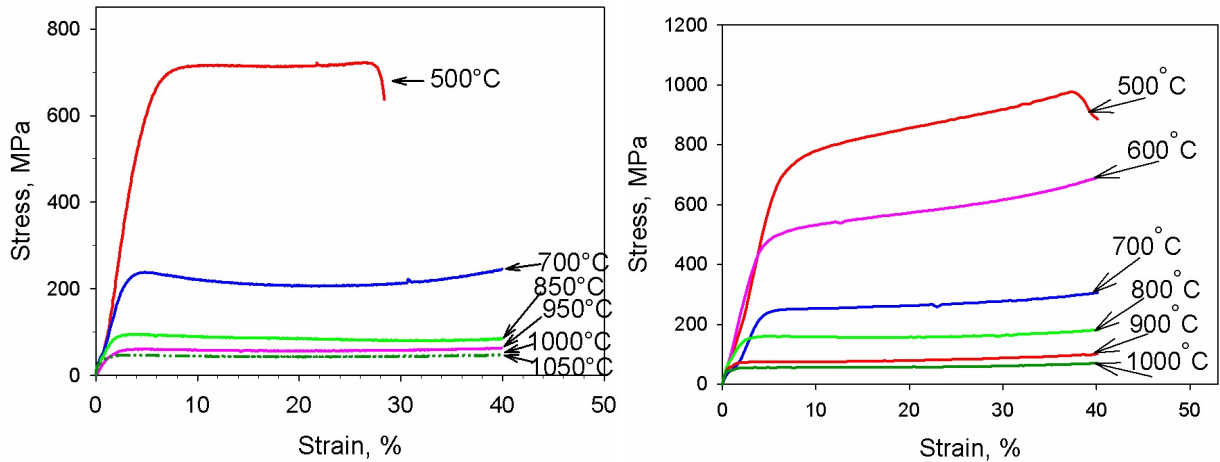

b

Figure 2. Flow curves obtained during compression at $500-1050^{\circ} \mathrm{C}$ of the $\mathrm{Ti} / \mathrm{TiB}$ (a) or at $500-1000^{\circ} \mathrm{C}$ of the $\mathrm{Ti}-15 \mathrm{Mo} / \mathrm{TiB} \mathrm{MMC}(\mathrm{b})$; a nominal strain rate was $10^{-3} \mathrm{~s}^{-1}$ in both cases.

Mechanical behavior of the composites during compression (Fig. 2) can be used for the estimation of optimal temperature-rate parameters for hot working Processing maps show areas where the deformation capacity of the material is maximal (for example, the regions of dynamic recrystallization or superplasticity), as well as regions corresponding to unstable plastic flow or cracks formation [16]. To this end processing maps with strain rate sensitivity $\mathrm{m}=\Delta \log \sigma / \Delta \log \varepsilon^{\prime}$ (where $\sigma$ is the flow stress and $\varepsilon^{\prime}$ is the strain rate) was constructed. The efficiency of power dissipation ( $\eta$ ) of a work piece can be estimated by comparing its power dissipation through 
microstructural changes with that occurring in an ideal linear dissipator $(\mathrm{m}=1)[17]$ :

$\eta=(\mathrm{m} /(\mathrm{m}+1)) / 0.5=2 \mathrm{~m} /(\mathrm{m}+1)$

The power dissipation map represents the projection of a three-dimensional surface describing the variation of $\eta$ (isolines at the maps) with temperature and strain rate on the $\mathrm{T}-\dot{\varepsilon}$ plane.

Figure 3 shows processing maps constructed on the base of results obtained at the true strain $\varphi=1.2$. Both maps expectably suggest optimal working parameters at high temperatures and low strain rates. However the minimum deformation temperatures at which stable deformation without strong flow localization or cracking can be performed was found to be quite different: in the case of $\mathrm{Ti} / \mathrm{TiB}$ the minimum temperature of hot working is $\sim 700^{\circ} \mathrm{C}$ while $\mathrm{Ti}-15 \mathrm{Mo} / \mathrm{TiB}$ can be processed at $600^{\circ} \mathrm{C}$. To establish further the effect of hot working on the structure and properties of the MMCs, multiaxial forging of both composites at $700^{\circ} \mathrm{C}$ to the total strain $\sim 5.2$ was carried out.

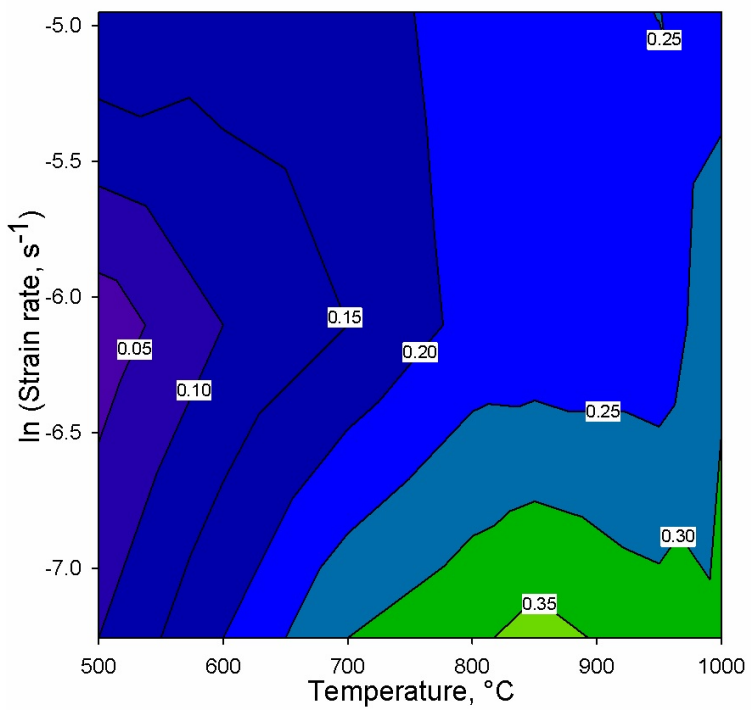

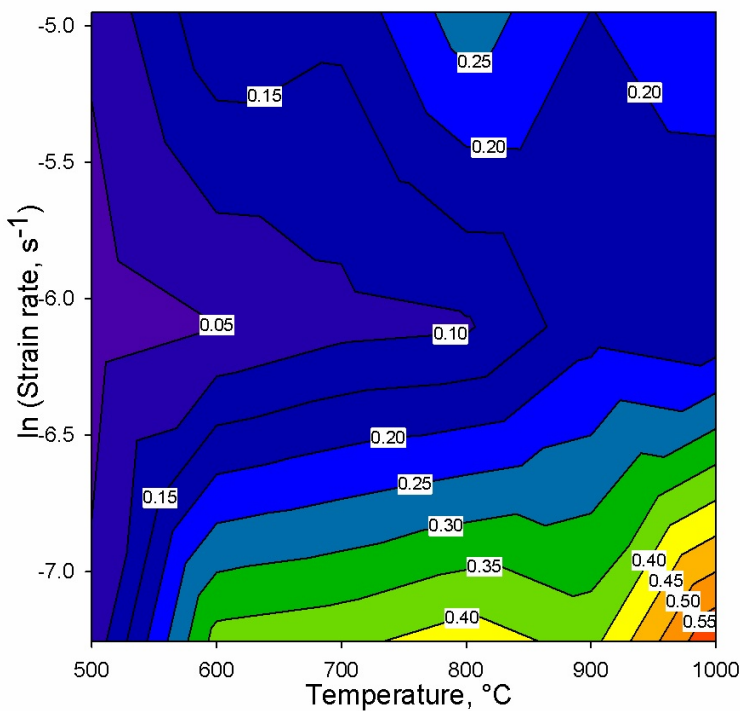

b

Figure 3. Processing maps of the Ti/TiB (a) or Ti-15Mo/TiB (b) composites at a true strain $\varphi=1.2$.

True stress-true strain curves obtained during multi-axial isothermal forging at $700^{\circ} \mathrm{C}$ of the $\mathrm{Ti} / \mathrm{TiB}$ and $\mathrm{Ti}-15 \mathrm{Mo} / \mathrm{TiB} \mathrm{MMC}$ are shown in Fig. 4. For each $\mathrm{MMC}$ the stress-strain curves during the first compression exhibited an initial hardening transient, a peak flow stress, and then pronounced flow softening. In the case of Ti-15Mo/TiB this softening was followed by strengthening again and considerable strengthening was observed at each next deformation step. Although a qualitatively similar behavior was observed for $\mathrm{Ti} / \mathrm{TiB}$ (strengthening at each next deformation step) the increment in flow stress was greater in the case of Ti-15Mo/TiB. Nevertheless in general flow stress at the final step of MAF was similar to that at the initial stages thereby suggesting a balance between strengthening and softening processes. It worth noting also, that the flow stress was approximately $\sim 2$ times higher for Ti-15Mo/TiB MMC than that for Ti/TiB composite.

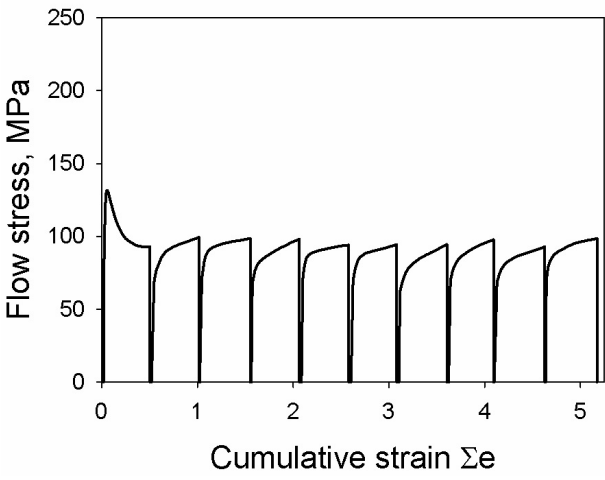

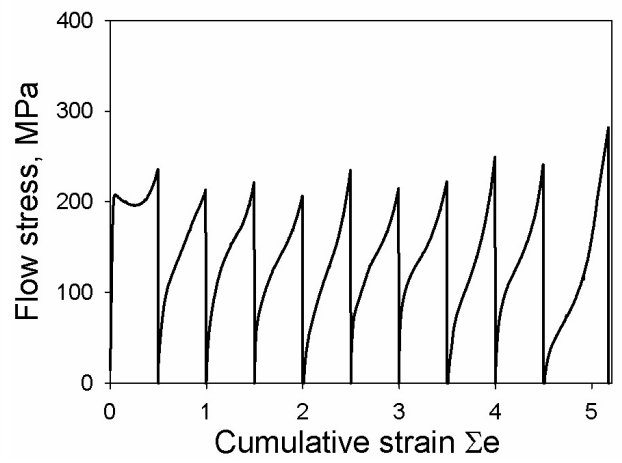

b

Figure 4. Cumulative true strain obtained during the multi-axial isothermal forging at $700^{\circ} \mathrm{C}$ of the Ti/TiB (a) and Ti-15Mo/TiB MMC (b).

Microstructure evolution of the MMCs during MAF was mainly associated with the formation of a developed (sub)grain structure in the matrix of both composites and appearance of a large number of TiB debris (Fig. 5, 7). The average length of the TiB whiskers dropped after the first step of MAF in both cases and then monotonously decreases as the accumulated strain increased (Fig. 6). The debris of TiB whiskers was $\sim 2$ times longer in Ti-15Mo/TiB MMC in comparison to that of Ti/TiB. 


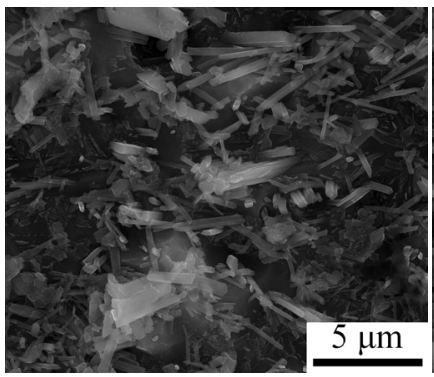

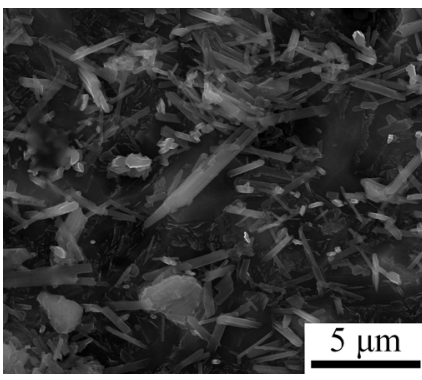

a

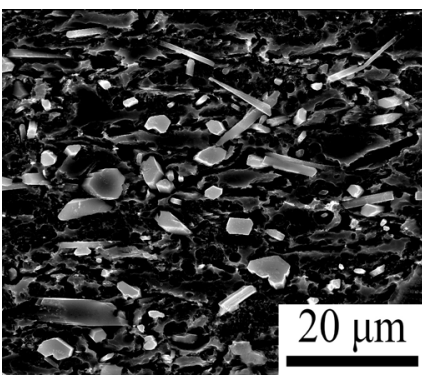

b

Figure 5. SEM images of Ti/TiB (a, b) and Ti-15Mo/TiB (c) MMC subjected to 5 (a) and 10 (b, c) steps of MAF at $700^{\circ} \mathrm{C}$.

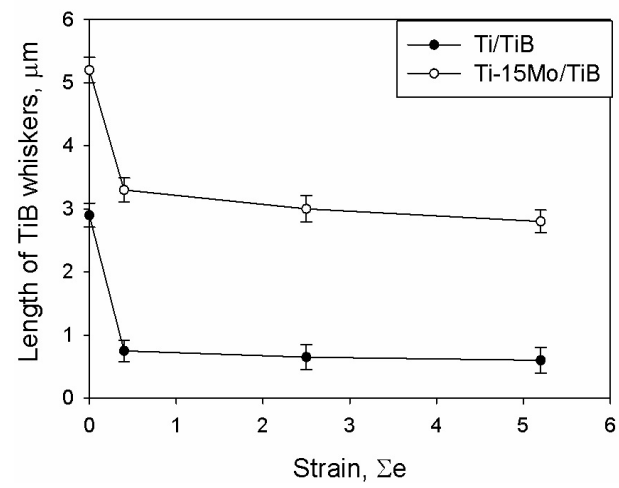

Figure 6. Apparent length of TiB whiskers in Ti/TiB or Ti-15Mo/TiB MMCs during MAF at $700^{\circ} \mathrm{C}$.

TEM analysis shows that MAF of $\mathrm{Ti} / \mathrm{TiB}$ at $700^{\circ} \mathrm{C}$ to $\mathrm{e}=2.6$ ( 5 steps $)$ resulted in the formation of nearly dislocation-free areas $(0.5-1 \mu \mathrm{m}$ in diameter) in a deformed matrix (Fig. 7a). The estimated dislocation density in these areas was $\sim 2 \times 10^{12} \mathrm{~m}^{-2}$. The size and volume fraction of such areas increases when the accumulated strain reaches $\mathrm{e}=5.2$ (10 steps) during MAF (Fig. 7b) that can be associated with the development of continuous dynamic recrystallization. The microstructure of the Ti-15Mo/TiB composite after 10 steps of MAF did not contain obvious recrystallized areas thereby suggesting that the microstructure development can be associated with other mechanisms (for example phase transformation) during MAF (Fig. 7c). However further studies are needed to clarify this question.

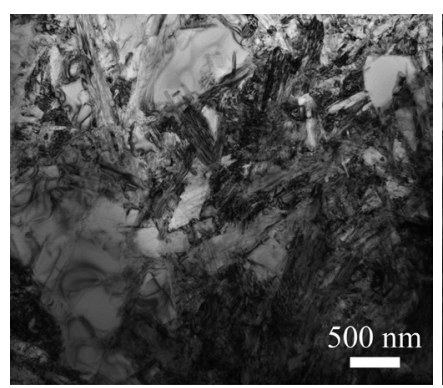

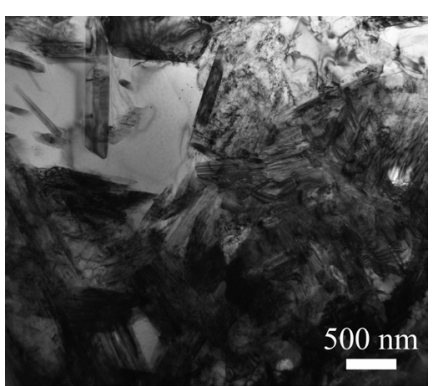

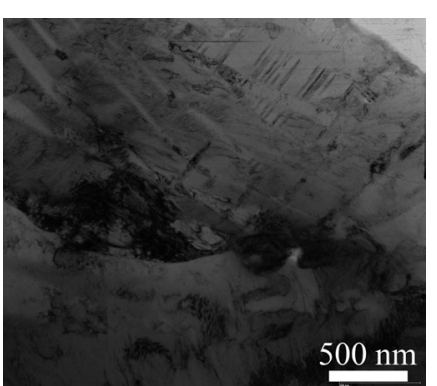

c

Figure 7. TEM images of $\operatorname{Ti} / \operatorname{TiB}(a, b)$ and $\operatorname{Ti}-15 M o / T i B(c)$ MMC subjected to 5 (a) and 10 (b, c) steps of MAF at $700^{\circ} \mathrm{C}$.

\section{Conclusions}

1. The initial microstructure of the $\mathrm{Ti} / \mathrm{TiB}$ and $\mathrm{Ti}-15 \mathrm{Mo} / \mathrm{TiB}$ composites consisted of the $\mathrm{TiB}$ whiskers heterogeneously distributed within the hep Ti (in $\mathrm{Ti} / \mathrm{TiB}$ ) or bec $\mathrm{Ti}$ (in $\mathrm{Ti}-15 \mathrm{Mo} / \mathrm{TiB}$ ) matrix. The average diameter of the TiB whiskers was $36 \pm 15$ and $130 \pm 65 \mathrm{~nm}$, the spacing between the TiB whiskers was $\sim 0.2-0.3$ and $\sim 0.5-0.7 \mu \mathrm{m}$, respectively.

2. Processing maps for both MMCs were constructed on the basis of uniaxial compressions in the interval of temperatures $500-1050^{\circ} \mathrm{C}$. The minimum processing temperature was found to be $700^{\circ} \mathrm{C}$ for $\mathrm{Ti} / \mathrm{TiB}$ and $600^{\circ} \mathrm{C}$ for $\mathrm{Ti}-15 \mathrm{Mo} / \mathrm{TiB}$.

3 . For each MMC considerable strengthening was observed at each next deformation step during MAF at $700^{\circ} \mathrm{C}$. Flow stress during multiaxial forging was $\sim 2$ times higher for $\mathrm{Ti}-15 \mathrm{Mo} / \mathrm{TiB} \mathrm{MMC}$ than that for Ti/TiB composite.

4. Microstructure evolution during MAF of both MMCs was associated with the formation of a developed (sub)grain structure in the matrix of both composites and appearance of a large number of TiB debris. Formation of areas with low dislocation density in Ti/TiB MMC suggest the development of continuous dynamic recrystallization.

\section{Acknowledgments}

This research was funded by the Russian Science Foundation (Grant Number 15-19-00165). The authors are grateful to the personnel of the Joint Research Centre, Belgorod State University for their assistance with the instrumental analysis.

\section{References}

[1] C. Leyens, M. Peters, Titanium and Titanium Alloys. Fundamentals and Applications, first ed. (2003).

[2] T. Saito, T. Furuta, T. Yamaguchi, Advances in Titanium Metal Matrix Composites, The Minerals, Metals \& Materials Society (1995). 
[3] K. Morsi, V.V. Patel, J. Mater. Sci. 42 (2007) 2037.

[4] A.V. Ragulya, In: Encyclopedia of Materials: Science and Technology (2010) 1.

[5] M. Ozerov, M. Klimova, A. Vyazmin, N. Stepanov, S. Zherebtsov, Mater. Lett. 186 (2017) 168-170.

[6] H. Feng, Y. Zhou, D. Jia, Q. Meng,; J. Rao, Cryst. Growth Des. 6 (2006) 1626-1630.

[7] M. Ozerov, N. Stepanov, A. Kolesnikov, V. Sokolovsky, S. Zherebtsov, Mater. Lett. 187 (2017) 28-31

[8] M. Ozerov, M. Klimova, A. Kolesnikov, N. Stepanov, S. Zherebtsov, Materials and Design 112 (2016) 17-26.

[9] V. Imayev, R. Gaisin, E. Gaisina, R. Imayev, H.-J. Fecht, F.Pyczak, Mater. Sci. Eng. A 609 (2014) 34-41.

[10] M. Ozerov;; M. Klimova,; V. Sokolovsky; N. Stepanov;; A. Popov,; M. Boldin,; S. Zherebtsov, J. Alloys Compd. 770 (2019) $840-848$

[11] R. A. Gaisin, V. M. Imayev, R. M. Imayev, and E. R. Gaisina, Russian Physics Journal 58 (2015) 848-853.

[12] M.S. Ozerov, M.V. Klimova, N.D. Stepanov, S.V. Zherebtsov, Materials Physics and Mechanics 38 (2018) 54-63.

[13] S. Zherebtsov, M. Ozerov, N. Stepanov, M. Klimova and Yu. Ivanisenko, Metals 7 (2017) 507.

[14] I. Weiss, S.L. Semiatin, Mater. Sci. Eng. A 243 (1998) 46-65.

[15] G.A. Salishchev, S.Yu. Mironov, S.V. Zherebtsov, Rev. Adv. Mater. Sci. 11 (2006) 152-158.

[16] K.P. Rao, Y.V.R.K. Prasad, Comprehensive Materials Processing 3 (2014) 327.

[17] Y.V.R.K. Prasad, S. Sasidhara, Hot Working Guide: a Compendium of Processing Maps (1997). 